\title{
Dental Health among Green Marble Mine Laborers, India
}

\author{
Rushabh J Dagli, Santhosh Kumar, Chandrakant Dhanni., Prabu Duraiswamy, Suhas Kulkarni
}

\section{ABSTRACT}

Objective: To determine the oral health status among Green Marble Mine laborers; to provide epidemiological data for planning and evaluation of oral health care programme.

Methods: The study area was divided into 4 geographic zones, and participants were selected by stratified cluster sampling technique. A total of 513 subjects were included in final study which were divided among the four age cohort (18-25, 26-34, 35-44, 45-more respectively), following the guidelines for research methodology recommended by WHO oral health surveys 1997. Clinical examination was conducted by one of the three examiners with the aid of an artificial light sorce. The agreement (kappa statistics) for diagnosis of DMFT and CPI was determined (field teams versus expert) $91.2 \%$ two days prior to the examination. Data was analyzed using Bivariate and multivariate analysis.

Results: The mean DMFT and DMFS scores were $(2.79 \pm 2.44)$ and $(5.47 \pm 5.40)$ respectively. The caries prevalence was $71.1 \%$ with maximum in 25-34 years while 148 participants were caries free. A higher prevalence of periodontal disease was present with only $1.75 \%$ having healthy gingiva. Mean number of sextant involved was maximum among 35-44 years. Alcohol and Stress due to physical load and noisy environment among laborers have shown highly significant relationship with CPI scores $(p<0.001)$. Fracture of tooth, mainly maxillary central incisor was high (10.5\%) as an occupational peril.

Conclusions: The findings highlighted the low caries prevalence, higher periodontal disease which requires primary anticipation. Prevention of tooth fracture and improvement of overall nutritional status, with stress reduction protocol should also be given consideration.

Key-words: Marble Mine laborers; Epidemiology; Dental caries; Periodontal disease; stress; tooth fracture

\section{Contact Author}

Dr. Dagli Rushabh Jayeshkumar

E-mail : rushabhjdagli@yahoo.com
$\mathrm{M}$ arble mining is one of the major industries flourishing through out the world. Till date no study has been attempted world wide concerning the oral health status of laborers working in this field. A large number of laborers work in the stone crushing and mining industry in India(1). In India, Rajasthan (kesheriyaji) is only the place where more green marble mines are found. As part of general health of these workers; their exposure to respirable crystalline silica and a number of other particulate matter exposure metrics in occupational settings but the physically tedious work drives people to consume alcohol and tobacco, which devour a significant portion of their meagre income. This mine workers are highly associated with tobacco habits which causes deterioration of there oral health too, so this population was selected as no previous oral health study has been done among them who are much habitual to tobacco. In the present study there were no female workers due to the heavy physical work load involved. 
The whole community is plagued by malnutrition, ill health and physical impediments from accidents. A mineworker, on an average, finishes his life at the age of 49.3 years - 10 years earlier than those outside the mines (Mines and Geology Department - The Government of Rajasthan). Moreover, the dust swirling around in quarries is mineral powder that causes a number of lung diseases, such as silicosis, tuberculosis (TB), silico-tuberculosis and asthma. Exposure to chemical, physical, and biological agents in the workplace can result in adverse effects on workers ranging from simple discomfort and irritation to debilitating occupational diseases such as lung fibrosis, neuropathy, deafness, organ damage, and cancers of various sites(2), so it was also essential to know through the present study that any occupational disease related to oral health is prevalent among laborers or not.

For the oral health of general population, at global level marked changes in oral disease pattern has been observed over past decades $(3,4)$. More recently the meta- analysis of oral health report of the studies carried out, over past 40 years revealed contrasting disease trend, depending upon country population group, and socio-economical condition(5).During the last 1015 years evidence has accumulated in several western industrialized countries, in encouraging trends in prevalence and severity of dental disease(6,7). Majority of people living in rural areas have limited access to essential oral health care due to geographic and economic barrier $(8,9)$. Various previous studies suggest that cigarette smoking and alcohol drinking co- existing in a significant proportion of male adolescent will have major implication on oral disease(10).In the region of Udaipur district one survey was conducted earlier by Bali(11) et al(2002), which have reported that the standard of oral hygiene for adults was poor, bleeding and calculus problems were frequent $(17.6 \%)$ whereas prevalence rate of advanced periodontal disease were low $(0.9 \%)$ while dental caries experience was present among $67.5 \%$ of people from which DMFT between 1-3 were $49.7 \%$, but this population differs considerably from the present study of marble mine workers who are more backward socio-economically compared to general population of Udaipur district.

In an era of evidence based medicine and oral health, scientifically testing such a fundamental concept of the prevalence of caries and periodontal disease among specific occupational people in rural areas, should be given highest research priority as very few researches dealing with the prevalence of dental disorders have been carried out among Indian population, especially with rural subjects(12) and specific occupation.

\section{Method}

Rajasthan consists of many marble mines from which marble is Exported all over the world. The study has been conducted by the department of preventive and community dentistry,
Darshan dental college, known as the "First Rajasthan Mines Oral Health Study", was intended as an inventory of the present state of the oral health, oral-health related behavior and use of dental treatment services of the mine workers population of Rajasthan, India. Recording of oral health status was one part of this study and this paper solely focuses on these results.

Keshriyaji is the place where all the green marble mines are located. It is divided into four geographic zones namely Masoroi ki obri (south -east), Rushabhdev (north -east), khandiovri (south-west), and kagdar bhatiya (north -west). Except the possibility of treatment in major hospitals at Udaipur, there is no public support for the population regarding dental health at keshriyaji.

The minimum sample size required for this survey was based on the lowest prevalence of a significant target lesion observed in previous surveys, but as no previous studies were conducted for oral health among these population, so WHO sampling procedure (stratified cluster sampling procedure) was used to collect the representative population for a cross sectional study $(13,14)$. With the help of marble mine owners association a special leave was granted for the workers. The total population of mine workers provided by owners of mines association from all the four geographic zones were 4832 mine workers in total 29 mines, and from each zone 2 mines were randomly selected where all the present workers were examined. Hence of total eight mines in all four regions total 521 workers were examined, 8 workers $(1.53 \%)$ were dropped out for quality-neutral reasons who were having medically compromised condition(15). The net random sample was obtained by deducting these from the gross random sample so the remaining 513 males which were included in the present study.

The study was done in the month of February, 2007 for which prior permission was got from the concerned authorities to prevent any inconvenience from marble mine owners and workers. Ethical clearance was obtained prior to the survey from " Ethical Committee of Research" of Darshan Dental College and Local Health Authorities. The informed consent of each patient was taken prior to recording oral health.

The oral cavities were examined using additional artificial light. For the diagnosis of dental caries, WHO type III examination was done using mouth mirrors and sharp probes while Periodontal assessments were done by CPI-probes. The "WHO oral health Performa-1997" was used to record the demographic information.

All clinical data were recorded by three trained project teams each consisting of a dentist, a dental nurse and a recording assistant. Recording of data of dental caries and periodontal disease was based on publications of the World Health 
Organization(WHO)(16). In addition the International Classification of Diseases for Dentistry (ICD-DA)(17) was also used for the same.

All three teams had undergone a full day's theoretical and practical training by the senior dental calibrator prior to the commencement of the project. To verify that the data obtained were of sufficient quality. Reliability studies were carried out by the participating project calibrator during the field work. The agreement (kappa statistics) for (field teams versus expert) two days prior to the examination for dental caries and periodontal diseases were 0.91 and 0.87 respectively.

The set of independent variables was collected mainly from a structured, self-administered questionnaire in local language to mine laborers. For the nutritional status of them, height and weight was recorded for all the participants and BMI(Body

Mass Index) was calculated.

The data collected was analyzed using Analysis of Variance(ANOVA), Chi-Square test, Multiple Logistic Regression Analysis and Scheffe's test. Two models were developed to determine variables those were significantly associated with the outcomes of dependent variables; dental caries and periodontal disease. For the models, the explanatory variables included were the following :

- Age

- Nutritional status.

- Oral hygiene practices

- Tobacco habits.

- Alcohol habits.

- Stress

$\mathrm{p}<0.05$ was accepted as statistically significant and $\mathrm{p}<0.01$ was set to be highly statistically significant. The statistical analysis was performed using the SPSS(10.0) software package.

\section{Results}

(Table 1) shows the overall demographic and medical

\section{Table 1: Profile of the mine laborers}

\section{- Age groups}

$18-25$

171

162

26-34

$35-44$

135

33.3

45-above

45

26.3

8.7

- Nutrition status (Body Mass Index)

Normal nutrition(BMl>20)

Marginal(BMI=18.5-20)

Malnutrition(BMI<18.5)

$171 \quad 33.3$

$144 \quad 28.1$

$198 \quad 38.6$

- Oral hygiene practice

Cleans their teeth daily

Doesn't clean their teeth daily

405

78.9

- Stress

Feeling stressful at work

108

21.1

Doesn't feel stressful life

333

180

64.9

- Tobacco habits

Non-Users

Regular-users

Occasional users

Ex-users

225

207

45

36

- Alcohol habits

Non- drinkers

Regular-drinkers

Occasional drinkers

Ex-drinkers

378

73.7

$81 \quad 15.8$

$45 \quad 8.8$

- Fracture of tooth

Having fractured 1 or more tooth

Doesn't have any fracture tooth

54

459

10.5

89.5

characteristic of the Marble Mine laborers. 18-24 age group of mine workers were highest proportion of $33.3 \%$. Malnutrition was among 38.6\% laborers. $21.1 \%$ of laborers were not cleaning their teeth daily. About $65 \%$ of workers were experiencing stressful life as mine-laborers. Regular Tobacco and Alcohol habits were among $40.3 \%$ and $15.8 \%$ laborers respectively and a higher prevalence $(10.5 \%)$ of Fracture of tooth (mainly maxillary central incisor), was found among laborers.

(Table-2) The mean DMFT and DMFS scores were Table 2: Prevalance of dental caries among marble mine laborers according to age group

\begin{tabular}{|c|c|c|c|c|c|c|c|c|c|}
\hline Age & & DT & MT & FT & DMFT $^{\star}$ & DS & MS & FS & DMFS $†$ \\
\hline \multirow[t]{2}{*}{$18-25$ years $(n=162)$} & Mean & 2.63 & 0.16 & 0.00 & 2.58 & 3.32 & 0.79 & 0.00 & 4.11 \\
\hline & SD & 2.82 & 0.49 & 0.00 & 2.99 & 3.46 & 2.45 & 0.00 & 4.42 \\
\hline \multirow[t]{2}{*}{$26-34$ years $(n=162)$} & Mean & 3.11 & 0.33 & 0.00 & 3.44 & 4.17 & 1.76 & 0.00 & 5.83 \\
\hline & SD & 2.09 & 0.67 & 0.00 & 2.25 & 2.74 & 3.42 & 0.00 & 4.32 \\
\hline \multirow[t]{2}{*}{$35-44$ years $(n=135)$} & Mean & 1.80 & 0.33 & 0.00 & 2.13 & 2.87 & 1.67 & 0.00 & 4.53 \\
\hline & SD & 1.52 & 0.60 & 0.00 & 1.71 & 2.34 & 2.99 & 0.00 & 4.43 \\
\hline \multirow[t]{2}{*}{$45 \&$ more years $(n=45)$} & Mean & 1.20 & 2.00 & 0.00 & 3.20 & 2.20 & 10.00 & 0.00 & 12.20 \\
\hline & SD & 1.49 & 1.81 & 0.00 & 1.96 & 3.03 & 9.05 & 0.00 & 8.87 \\
\hline \multirow[t]{2}{*}{ Total $(n=513)$} & Mean & 2.44 & 0.42 & 0.00 & 2.79 & 3.37 & 2.14 & 0.00 & 5.47 \\
\hline & SD & 2.28 & 0.92 & 0.00 & 2.44 & 2.99 & 4.62 & 0.00 & 5.40 \\
\hline
\end{tabular}


Table 3: Gingival and periodontal assessment by using CPI scores according to age group

\begin{tabular}{|lccccc|} 
& \multicolumn{5}{c|}{ Number and percentage of person coded $\neq$} \\
\cline { 2 - 6 } Age group(=n) & Healthy gingiva & Bleeding & Calculus & Shallow Pocket & Deep Pocket \\
\hline $18-25(171)$ & $9(5.2)$ & $99(57.8)$ & $45(26.3)$ & $18(10.5)$ & 0 \\
$26-34(162)$ & 0 & $63(38.8)$ & $81(50.0)$ & $18(11.1)$ & 0 \\
$35-44(135)$ & 0 & $45(33.3)$ & $54(40.0)$ & $27(20.0)$ & $9(6.7)$ \\
45 and more (45) & 0 & $27(60.0)$ & $9(20.0)$ & $9(20.0)$ & 0 \\
$\ddagger \mathrm{c}^{2}=144.05$, d.f. $=12, \mathrm{p}<0.001(\mathrm{HS})$ & & & & \\
\end{tabular}

Table: 4: Mean number of sextants affected by periodontal condition

\begin{tabular}{|c|c|c|c|c|c|}
\hline \multirow[b]{2}{*}{ Mean number of sextants } & \multicolumn{5}{|c|}{ Age group in years } \\
\hline & $18-25$ & $26-34$ & $35-44$ & 45 and & Total more \\
\hline No periodontal disease & 0.8 & 0.4 & 0 & 0 & 0.30 \\
\hline Bleeding or higher $(1+2+3+4)$ & 5.2 & 5.6 & 6.0 & 6.0 & 5.70 \\
\hline Calculus or higher $(2+3+4)$ & 2.7 & 3.7 & 4.1 & 2.3 & 3.20 \\
\hline Shallow pocket or higher $(3+4)$ & 0.7 & 0.8 & 1.6 & 0.6 & 0.92 \\
\hline Deep pocket(4) & 0.0 & 0.1 & 0.4 & 0.0 & 0.15 \\
\hline Excluded (X) & 0.0 & 0.1 & 0.2 & 0.0 & 0.07 \\
\hline $\operatorname{Mean}( \pm$ S.D) & $\begin{array}{c}1.45 \\
( \pm 0.81)\end{array}$ & $\begin{array}{c}1.69 \\
( \pm 0.76)\end{array}$ & $\begin{array}{c}1.99 \\
( \pm 0.88)\end{array}$ & $\begin{array}{c}1.52 \\
( \pm 0.67)\end{array}$ & $\begin{array}{c}1.67 \\
( \pm 0.83)\end{array}$ \\
\hline
\end{tabular}

$(2.79 \pm 2.44)$ and $(5.47 \pm 5.40)$ respectively. The caries prevalence was $71.1 \%$ of all the age group with maximum in 25-34 years group while 148 participants were caries free. None of the participant had filled teeth.

(Table 3) and (Table 4) illustrates the periodontal status among the study population and shows a very high prevalence of periodontal disease. Only 5.2\% of 18-25 years participants having healthy gingival and with increasing age the gingivitis was progressing to periodontitis. Mean no of sextant involved was higher among 35-44 years(1.99 \pm 0.88$)$ than other age group.

(Table-5) Multiple logistic regression analysis model of mean

Table 5: Multiple logistic regression analysis model of DMFT among marble mine laborers showing likelihood ratio test

\begin{tabular}{|lcrrr|}
\hline Effect & $\begin{array}{c}\text { 2 Log Likehood } \\
\text { of Reduced } \\
\text { Model }\end{array}$ & $\begin{array}{c}\text { Chi- } \\
\text { Square }\end{array}$ & df & §Sig. \\
\hline Age & 1327.130 & 584.539 & 27 & .000 \\
Nutrition & 1078.451 & 335.860 & 18 & .000 \\
Oral Hygiene & 811.510 & 68.920 & 9 & .000 \\
Stress & 768.904 & 26.313 & 9 & .002 \\
Tobacco & 1056.873 & 314.282 & 27 & .000 \\
Alcohol & 920.840 & 178.249 & 27 & .000 \\
§P<0.01 (HS) & & & & \\
\hline
\end{tabular}

DMFT was increasing with increased age, malnutrition, poor oral hygiene practice, stress, and habits of tobacco and alcohol. $(\mathrm{p}<0.01)$.

(Table 6) Multiple Logistic Regression Analysis model for mean CPI was increased with alcohol habits and stress. $(\mathrm{p}<0.01)$

(Table 7) Comparison of mean shows those 26-35 years age group is having significant higher mean difference for DMFT $(p<0.05)$ indicating higher severity of disease among 26-35 years.

(Table-8) Comparison of mean shows that 35-44 year age group

Table 6: Multiple Logistic Regression Analysis model for CPI among marble mine laborers showing likelihood ratio tests

\begin{tabular}{|lrrrr|}
\hline Effect & $\begin{array}{c}\text { 2 Log Likehood } \\
\text { of Reduced } \\
\text { Model }\end{array}$ & $\begin{array}{c}\text { Chi- } \\
\text { Square }\end{array}$ & df & Sig. \\
\hline Age & 6976.255 & -26942.878 & 45 & 1.000 \\
Nutrition status & 697.629 & -33221.504 & 30 & 1.000 \\
Oral hygiene & 16721.477 & -17197.656 & 15 & 1.000 \\
Stress & 40828.790 & 6909.657 & 15 & $0.000^{*}$ \\
Tobacco & 24339.155 & -9579.979 & 45 & 1.000 \\
Alcohol & 54663.699 & 20744.565 & 45 & 0.000 \\
& & & & \\
${ }^{*} \mathrm{P}<0.01(\mathrm{HS})$. & & & & \\
\hline
\end{tabular}


has significant higher mean difference than all other three age groups for CPI $(\mathrm{p}<0.05)$ indicating higher severity of periodontal disease for 35-44 years.

\section{Discussion}

The relatively small population investigated, and the highly selective occupational character of this population makes comparison with other epidemiological studies precarious and the result should be interpreted with great caution.

The intention of study was to provide systematic information on oral health of marble mine workers, in a region of keshariyaji and that result would aid in the planning and evaluation of oral health promotion programmes. Moreover, a Comparable prevalence data have not been recorded previously worldwide; so to gather this data for comparing prevalence of lesions among other population of India and other countries. Rationale for this comparison was that, former Indian population especially workers differed considerably - occupationally, politically, socially and particular in health care utilization comparing to other country. It was therefore expected that differences in occupation, lifestyle and healthcare utilization would have an effect on dental health.

For the present study stratified cluster sampling procedure was used to achieve representative sample and it incorporates the sufficient examination sites of all four geographic locations at keshariyaji. The study was designed as an epidemiological survey of the cross-sectional study type based on representative samples of the population taken from the age cohorts 18-25 year-olds, 26-34 year-olds, 35-44- year- old, and 45-above-year-olds. There were no mine workers below 18 years of age and lesser number of representative populations of older age above 45 years was found in the present study as the work is more associated with physical load, less old aged workers were there.

The stress was higher among laborers which was due to higher

Table 7: Multiple Comparisons of Dependent Variable: DMFT by Scheffe's test

\begin{tabular}{|llccc|}
\hline Age(I) & Age(J) & Mean Difference (I-J) & Std. Error & Sig. \\
\hline $18-25$ & $26-34$ & $-.87(\%)$ & .26 & .013 \\
& $35-44$ & .45 & .27 & .452 \\
& $45-$-above & -.62 & .40 & .491 \\
$26-34$ & $18-25$ & $.87(\%)$ & .26 & .013 \\
& $35-44$ & $1.31(\%)$ & .28 & .000 \\
& $45-a b o v e$ & .24 & .40 & .946 \\
$35-44$ & $18-25$ & -.45 & .27 & .452 \\
& $26-34$ & $-1.31(\%)$ & .28 & .000 \\
& $45-a b o v e$ & -1.07 & .41 & .082 \\
$45-$-above & $18-25$ & .62 & .40 & .491 \\
& $35-44$ & -.24 & .40 & .946 \\
& $45-a b o v e$ & 1.07 & .41 & .082 \\
\%The mean difference is significant at the 0.05 level &
\end{tabular}

physical load, noisy environment, and poor economic status. Tobacco habits were recorded in local language of mine workers which is easy for them to communicate and thereby more reliable data for tobacco habits have been achieved. Alcohol habits were also recorded for all mine workers as a potential confounding factor with tobacco in the present study. There might be an under presentation of tobacco and alcohol habits by mine workers The risk associated with tobacco use can also be modified by other exposures such as diet, alcohol consumption, and genetics(18-20).

Malnutrition was higher which was further worsening oral health of laborers. The etiology and pathogenesis of periodontal disease involve a complicated interplay between the plaque etiological agents and various genetic and environmental risk factors, and its occurrence is often unpredictable $(21,22)$.

Facture of central incisors having prevalence(10.5\%) found in present study was due to impact on front teeth while falling down during working on wet and smooth marble surfaces it is the principle hidden occupational hazard related to oral health explored through present study.

\section{Caries status}

The Decayed Missing Filled Surfaces/Teeth (DMF) index has been in use for about 65 years, and is well established as the leading measure of caries experience in dental epidemiology(23).The mean DMFT and DMFS scores were $(2.79 \pm 2.44)$ and $(5.47 \pm 5.40)$ respectively in present study. The comparison of present study can be done with other workers and general adult population as no previous comparable data is available for this mine-workers occupation group. Bakery and chocolate factory workers (Masalin Ket al(24). in 1990 and Poul Erik Petersen et al(25). In 1983) have shown increases the prevalence of dental caries among workers with more years of work. Benoit Varenne et al (5) (2004)has found mean DMFT 6.3, and_in 35-44 years age group in western Africa. A survey

Table 8: Multiple comparision of Dependent Variable: CPI by Scheffe's test

\begin{tabular}{|llccc|}
\hline Age(I) & Age(J)Mean Difference (I-J) & Std. Error & Sig. \\
\hline $18-25$ & $26-34$ & -.24 & $8.81 \mathrm{E}-02$ & .065 \\
& $35-44$ & $-.54(\#)$ & $9.25 \mathrm{E}-02$ & .000 \\
& $45-$-above & $-7.26 \mathrm{E}-02$ & .13 & .962 \\
$26-34$ & $18-25$ & .24 & $8.81 \mathrm{E}-02$ & .065 \\
& $35-44$ & $-.30(\#)$ & $9.36 \mathrm{E}-02$ & .015 \\
& $45-$-above & .17 & .14 & .685 \\
$35-44$ & $18-25$ & $.54(\#)$ & $9.25 \mathrm{E}-02$ & .000 \\
& $26-34$ & $.30(\#)$ & $9.36 \mathrm{E}-02$ & .015 \\
& $45-$-above & $.47(\#)$ & .14 & .010 \\
$45-a b o v e$ & $18-25$ & $7.26 \mathrm{E}-02$ & .13 & .962 \\
& $35-44$ & -.17 & .14 & .685 \\
& $45-a b o v e$ & $-.47(\#)$ & .14 & .010 \\
\multirow{5}{*}{ \# The mean difference is significant at the 0.05 le } \\
\end{tabular}

JOHCD • www.johcd.org • January 2008;2(1) 
of Australian Army recruits by Hopcraft M et al (26) (2003) showing mean DMFS scores of 6.4, 9.1, 18.2 and 24.0 for subjects aged 17-20, 21-25, 26-30 and 31-35 years respectively. The present study has shown less prevalence of dental caries compared to previous studies of 35-44 years by Aleksejuniene $\mathrm{J}$ et al. (27) and Vrbic $\not \mathrm{V}(28)$ but the prevalence of DMFT of Udaipur district (2003) by R.K.Bali et al (11) shown 2.8 in rural and 2.9 in urban areas among subjects of $35-44$ years which is similar to the present study which confirms that there was no occupational related decline in caries experience. The water fluoride level of keshariyaji was found optimum between $0.82-1.51 \mathrm{ppm}$ in all four regions by the Ground Water Department of Udaipur district in 2004-05 which might also be the reason for lower caries experience among these special occupational group.

\section{Periodontal status}

The previous survey of Udaipur district by R.K.Bali et al. (11), have shown the higher prevalence of periodontal disease in Udaipur district in 35-44 years age group (83.7\%) than other age groups. The present study has shown $98.25 \%$ prevalence of periodontal disease with similar higher prevalence of 3544 years laborers which is more than general population of Rajasthan. Similar findings were reported by studies done by Satoshi Shizukuiski et al(29) in Japan(1998), that $92.6 \%$ of industrial workers had gingival or periodontal disease but studies conducted by Srikandi TW and Clarke NG (30) in Australia(1982) reported $100 \%$ prevalence of periodontal disease among workers. Benoit Varenne et al (2004)have also found CPI score-2(gingivitis and calculus) in $49 \%$ and score3 (shallow pocket) in $10 \%$ of population in $35-44$ years age group in western Africa(5).

The multiple logistic regression analysis has shown significant relationship by alcohol and stress on periodontal disease prevelance. The higher stress arising due to physical work load and noisy environment have shown occupational related increased prevalence of periodontal disease. Chronic smoking is associated with a lower systemic status of several B vitamins, reduced oral folate, and changes in folate form distribution in the mouth(31). Buccal cell concentrations of the carotenoids, retinoids, and tocopherols were generally lower in heavy smokers versus light smokers(32), which increases the susceptibility of periodontal disease and might be the reason of having higher incidence of periodontal disease in smokers group.

The result of this study was to be used in the planning and evaluation, of oral health promotion activity, being a part of general health care action plan at district level.

\section{Conclusion}

As a revitalization of existing oral health service which is mainly of treatment aspect, should be oriented more towards preventive health care. We conclude that in such population's continuous research and interventions are needed to improve the overall health status of these specific occupational subjects. Tools for intervention, rehabilitation and prevention includes public policies to discourage and restrict tobacco use through taxation, special measures should be evolved to prevent tooth fractures among this specific occupational group.

\section{Acknowledgements}

We sincerely thank and acknowledge "Keshariyaji Marble Mine Association" for their financial support and kind cooperation.

\section{THE AUTHORS}

\section{Dr. Rushabh J Dagli.}

BDS,

Lecturer,

Department of Preventive and Community Dentistry,

Darshan Dental College and Hospital,

Udaipur, Rajasthan, India. 313001.

Phone : +91-9928714501

Fax : +91-2942452273.

\section{Dr. Santhosh Kumar}

BDS,

Lecturer,

Department of Preventive and Community Dentistry, Darshan Dental College and Hospital,

Udaipur, Rajasthan, India. 313001.

\section{Dr. Chandrakant Dhanni}

BDS,

Lecturer,

Department of Preventive and Community Dentistry, Darshan Dental College and Hospital,

Udaipur, Rajasthan, India. 313001.

\section{Dr. Prabu Duraiswamy}

MDS

Associate professor,

Department of Preventive and Community Dentistry,

Darshan Dental College and Hospital,

Udaipur, Rajasthan, India. 313001

\section{Dr. Suhas Kulkarni}

MDS

Professor and Head of department,

Department of Preventive and Community Dentistry,

Darshan Dental College and Hospital,

Udaipur, Rajasthan, India. 313001

\section{References}

1. Sean Semple, David Green, Graeme McAlpine, Hilary Cowie and Anthony Seaton Exposure to particulate matter on an Indian stone crushing site Occup Environ Med. Published Online First: 6 August 2007.

2. D K Verma, J T Purdham and H A Roels, Translating evidence about occupational conditions into strategies for prevention.Occupational and Environmental Medicine 2002;59:205-214. 
3. Chen M Andersen RM, et al. Comparing oral health care system. A second International collaborative study. Geneva: World health organization 1997.

4. Brames DE. Indicators of oral health and their implication in developing countries. Int. Dent J 1983 ;33:60-66.

5. Benoit Varenne, Erik Petersen et al. Oral health status of children and adults in urban and rural areas of Burkin Faso, Africa, Int Dent $\mathrm{J},(2004) 54,83-89$.

6. Petersen P E, Kaka M, Oral Health Status of Children and Adult in Republic of Niger,Africa. Int Dental Journal 1999; 49:159-164.

7. M.J.Hahn, The dental status of workers on offshore installation, in the UK oil and gas industry. Br Dent. Journal 1987;163:262-264.

8. T. Blackmore, The dental health among single male hostel dwellers in leeds. Community Dental Health 1995 ;12:104-109.

9. R.R.Bhowate, Dental health among 11-15 year old children in Sevagram, Maharastra. Indian J. Dent. Res.1994; 5:65-68.

10. Seppo wickholm, Cigarette smoking, snuff use, and alcoho drinking: coexisting risk behaviors for oral health in young males. Community Dent. Health 2000, 17:47- 52

11. Bali et al.,National oral health survey and Fluoride Mapping 20022003,Dental council of India and Ministry of health and family welfare(Government of India),page no. 105.

12. Bhonsle RB, Murthi PR, Daftary DK, Mehta FS, An oral lesion in tobacco-lime users in Maharastra,India.J Oral Pathol. 1979 Feb;8:47-52.

13. Book: World Health Organization, oral health surveys-basic method, $3^{\text {rd }}$ edition, Geneva,WHO, 1987.

14. Book:World Health Organization., oral health surveys-basic method, $4^{\text {th }}$ ed., Geneva WHO, 1997.

15. Federation Dentaire International/ world health organization. Global goals of oral health by 2000 . Int Dent J. $1982 ; 32: 74-77$.

16. Federation Dentaire International/ world health organization. Global goals of oral health by 2000. Int Dent J. $1982 ; 32: 74-77$.

17. WHO. Application of the International Classification of Diseases to Dentistry and Stomatology (ICD-DA). 3 ed. Geneva: WHO; 1995.

18. Boyle P, Macfarlane GJ, Maisonneuve P, et al. Epidemiology of mouth cancer in 1989: a review. J R Soc Med. 1990;83:724-730.

19. McLaughlin JK, Gridley G, Block G, et al. Dietary factors in oral and pharyngeal cancer. J Natl Cancer Inst. 1988;80: 1237-1243.
20. Scully C. Oncogenes, tumor suppressors and viruses in oral squamous cell carcinoma. J Oral Pathol Med. 1993; 22:337-347.

21. Page RC, Kornman KS. The pathogenesis of human periodontitis: an introduction. J Periodontol 2000;14:9-11.

22. Clarke NG, Hirsch RS. Personal risk factors for generalized periodontitis. J Clin Periodontol 1995;22:136-45.

23. Broadbent JM, Thomson WM. For debate : problems with the DMF index pertinent to dental caries data analysis.Community Dent Oral Epidemiology 2005;33:400-9.

24. Masalin K, Murtomaa H, Meurman JH (1990):Oral health of workers in the modern Finnish confectionery industry. Community Dent Oral Epidemiol 18, 126-130.

25. Poul erik Petersen (1983):Dental health among workers at a Danish chocolatefactory.Community Dent Oral Epidemiol 11, 337-341.

26. Hopcraft M, Morgan MV. Exposure to fluoridated drinking water and dental caries experience in Australian Army recruits, 1996. Community Dent Oral Epidemiol 2003;31:68-74.

27. Aleksejuniene J, Eriksen HM, Holst D: Variation in caries and treatment experience in 35-44-year-old Lithuanians. Community Dent Oral Epidemiol 2000; 28;356-64.

28. Vrbic V: Reasons for the caries decline in Slovenia. Community Dent Oral Epidemiol 2000; 28: 126-32

29. Srikandi TW and Clarke NG. Periodontal status in a South Australian industrial population. Community Dent Oral Epidemiol 1982; 10: 272-275.

30. Satoshi Shizukuishi, Naoji Hayashi, Hiroo Tamagawa et al. Lifestyle and periodontal health status of Japanese factory workers, Ann Periodontol 1998;3:303-311.

31. Helen E Gabriel, Jimmy W Crott, Haifa Ghandour, Gerard E Dallal, Sang-Woon Choi, Mary K Keyes et al, Chronic cigarette smoking is associated with diminished folate status, altered folate form distribution, and increased genetic damage in the buccal mucosa of healthy adults.American Journal of Clinical Nutrition, 2006; 83 :835-841.

32. Helen E. Gabriel, Zhenhua Liu, Jimmy W. Crott, Sang-Woon Choi et al. A Comparison of Carotenoids, Retinoids, and Tocopherols in the Serum and Buccal Mucosa of Chronic Cigarette Smokers versus Nonsmokers, Cancer EpidemiologyBiomarkers \& Prevention 2006;15: 993-999. 